\title{
Utilization of in situ ELISA method for examining Trk receptor phosphorylation in cultured cells
}

\section{Antila, Hanna}

2014-01-30

Antila , H, Autio , H , Turunen , L, Harju , K, Tammela , P, Wennerberg , K, Yli-Kauhaluoma , J , Huttunen , H J , Castren , E \& Rantamaki , T 2014 , ' Utilization of in situ ELISA method for examining Trk receptor phosphorylation in cultured cells ' , Journal of Neuroscience Methods , vol. 222 , pp. 142-146 . https://doi.org/10.1016/j.jneumeth.2013.11.001

http://hdl.handle.net/10138/157612

https://doi.org/10.1016/j.jneumeth.2013.11.001

acceptedVersion

Downloaded from Helda, University of Helsinki institutional repository.

This is an electronic reprint of the original article.

This reprint may differ from the original in pagination and typographic detail.

Please cite the original version. 


\section{Short communication}

Utilization of in situ ELISA method for examining Trk receptor phosphorylation in cultured cells

Hanna Antila ${ }^{\mathrm{a}}$, Henri Autio ${ }^{\mathrm{a}}$, Laura Turunen ${ }^{\mathrm{b}}$, Kirsi Harju ${ }^{\mathrm{c}, 1}$, Päivi Tammela $^{\mathrm{d}}$, Krister Wennerberg ${ }^{\mathrm{b}}$, Jari Yli-Kauhaluoma ${ }^{\mathrm{c}}$, Henri J. Huttunen $^{\mathrm{a}, \mathrm{e}}$, Eero Castrén ${ }^{\mathrm{a}}$ and Tomi Rantamäki ${ }^{{ }^{*}}$

${ }^{a}$ Neuroscience Center, P.O. Box 56 (Viikinkaari 4), FI-00014 University of Helsinki, Finland; 'Institute For Molecular Medicine Finland (FIMM) P.O. Box 20 (Tukholmankatu 8), FI-00014

University of Helsinki, Finland

${ }^{\mathrm{c} D i v i s i o n}$ of Pharmaceutical Chemistry, Faculty of Pharmacy, P.O. Box 56 (Viikinkaari 5 E), FI00014 University of Helsinki, Finland;

${ }^{\mathrm{d}}$ Centre for Drug Research, Faculty of Pharmacy, P.O.Box 56 (Viikinkaari 5 E), FI-00014 University of Helsinki, Finland;

${ }^{\circledR}$ Hermo Pharma Ltd., Viikinkaari 4, FI-00790 Helsinki, Finland

\section{Abstract}

Background: Trk receptor tyrosine kinases regulate multiple important neuronal processes during the development and in the adulthood. Tyrosine phosphorylation of Trk serves as the initial step in the Trk signaling pathway and indicates receptor's autocatalytic activity. However, methods allowing simple and large-scale Trk phosphorylation analyses in cultured cells are lacking.

New Method: We describe an in situ phospho-Trk ELISA (enzyme-linked immunosorbent assay) method where cell culture, receptor stimulation and Trk phosphorylation analysis are all performed on the same multiwell plate.

Results: In situ phospho-Trk ELISA readily and specifically detects neurotrophininduced Trk phosphorylation in cultured cells. A proof-of-concept small molecule screening of a library composed of 2000 approved drugs and other bioactive compounds was carried out using this novel method.

Comparison with Existing Methods: In situ phospho-Trk ELISA utilizes the principles and advantages of conventional sandwich ELISA in an in situ context.

Conclusions: We describe a novel method that can be efficiently used to examine $\operatorname{Tr}$ receptor phosphorylation in cultured cells. Principally similar methods can be developed to examine the levels and signaling of any intracellular protein.

Keywords: BDNF; TrkB phosphorylation; ELISA; in situ

\section{1.}

\section{Introduction}

Tropomyosin-related kinases, Trks, serve as cognate receptors for neurotrophins: nerve growth factor (NGF) binds preferentially to TrkA, brain-derived neurotrophic factor (BDNF) and neurotrophin-4 (NT-4) to TrkB and neurotrophin-3 (NT-3) to TrkC (Huang and Reichardt, 2001). Trk receptor signaling regulates several important neuronal processes and abnormal Trk signaling is implicated in some cancers and in numerous nervous system disorders, including mood disorders, neurodegenerative disorders and pain (Rantamäki and Castrén, 2008; Thiele et al., 2009). Thus, pharmacological agents affecting endogenous Trk receptor signaling would hold significant therapeutic potential. Supporting this concept, the therapeutic actions of antidepressant drugs have been associated with their ability to activate TrkB receptors in the brain (Saarelainen et al., 2003; Rantamäki et al., 2007; Rantamäki and Castrén, 2008). Furthermore, experimental Trk receptor agonists provide neurotrophic support and ameliorate the neuropathological and behavioral outcomes in animal models of neurodegenerative disorders (Longo and Massa, 2013).

Upon activation, TrkB receptor is phosphorylated at specific intracellular tyrosine residues that further initiate intracellular signaling (Huang and Reichardt, 2001). TrkB phosphorylation is tightly associated with the receptor's catalytic activity and is thus widely used as an indicator of TrkB activation (Segal et al., 1996). The main purpose of this study was to set up and validate an in situ ELISA (enzyme-linked immunosorbent assay) method that can be efficiently used to examine Trk receptor phosphorylation in cultured cells. In this method the cells are directly cultured (and treated) on multiwell plates coated with the capturing antibody and, upon cell lysis, all subsequent assay steps are performed in situ. We describe several conditions that significantly increase the sensitivity of in situ ELISA to detect ligand induced Trk phosphorylation. In order to further validate the developed method and investigate its suitability for large-scale analyses, we performed a semi-automated small molecule screen with the Spectrum Collection, a chemical library with compounds of wide range of biological activities and structural diversity suitable for testing de novo assays.

* Address correspondence to: Dr. Tomi Rantamäki, Neuroscience Center, P.O. Box 56 (Viikinkaari 4), University of Helsinki, Finland. Fax: +358-9191 57620, E-mail: tomi.rantamaki@helsinki.fi

${ }^{1}$ Current address: Finnish Institute for Verification of the Chemical Weapons

Convention, Department of Chemistry, P.O. Box 55 (A. I. Virtasen aukio 1), FI-00014 University of Helsinki, Finland

\section{Materials and methods}

\subsection{Reagents and chemicals}

The Spectrum Collection compounds was purchased from MicroSource Discovery Systems, Inc. (Gaylordsville, CT, USA) and stored at $-80^{\circ} \mathrm{C}$ in DMSO stocks of $20 \mathrm{mM}$. The library consisted of 2000 compounds divided in three major groups: $50 \%$ drug or drug-like compounds, $30 \%$ natural products and $20 \%$ other bioactive compounds (for complete list visit: http://www.msdiscovery.com/spectrum.html). BDNF was purchased from Peprotech (Rocky Hill, NJ, USA), diluted in PBS (phosphate buffered saline; $\mathrm{pH}$ 7.4) containing $0.1 \%$ BSA (bovine serum albumin; Sigma Aldrich Finland, Helsinki, Finland) and stored in aliquots at $-80^{\circ} \mathrm{C}$. NGF (Promega, Madison, WI, USA) was kindly provided by Dr. Urmas Arumäe (University of Helsinki). The synthesis of 1NMPP1 (1-(1,1-dimethylethyl)-3-(1naphthalenylmethyl)-1H-pyrazolo[3,4- $d$ ]pyrimidin-4-amine) has been described previously (Sallert et al., 2009). Optacoat ${ }^{\mathrm{TM}}$ solution (catalog nro. C10202) was purchased from ALerCHEK Inc. (Springvale, Maine, USA). ProteoJETTM membrane protein extraction kit (catalog nro. K0321), chemiluminescence reagent (Pierce; catalog nro. 32106) and streptavidinHRP (catalog nro. 21126) were purchased from Thermo Fisher Scientific Oy (Vantaa, Finland). Trk kinase inhibitor K252a (Sigma Aldrich) was kindly provided by Dr. Heikki Rauvala (University of Helsinki). Detergents were purchased from Sigma Aldrich and prepared as 1\% (all, except Brij 35) or $0.1 \%$ solutions in buffer consisting of $137 \mathrm{mM} \mathrm{NaCl}, 20 \mathrm{mM}$ Tris, $10 \%$ glycerol, $50 \mathrm{mM} \mathrm{NaF}, 2 \mathrm{mM} \mathrm{Na} \mathrm{VO}_{4}$ and protease inhibitors (Complete inhibitor tablets, F. Hoffmann-La Roche Ltd., Basel, Switzerland)). 2.2. Cell culture

MG87-trkB fibroblasts (Vesa et al., 2000) (kindly provided by Dr. Eric Shooter, Stanford University) were cultured in Dulbecco's Modified Eagle's Medium (DMEM) (supplemented with $10 \%$ fetal calf serum, $1 \%$ penicillin/streptomycin, 1\% L-glutamine and $400 \mu \mathrm{g} / \mathrm{ml} \mathrm{G} 418)$. PC12 cells were cultured in DMEM/F12 media (1:1; Gibco 31330-038) (supplemented with $10 \%$ horse serum, $5 \%$ fetal calf serum, $10 \mathrm{mM}$ HEPES ( $\mathrm{pH} 7.2$ ), $5 \mathrm{mM}$ L-glutamine, $1 \%$ penicillin/streptomycin, $20 \mathrm{mM}$ sodium bicarbonate). The cell lines were maintained in a cell incubator $\left(5 \% \mathrm{CO}_{2}, 37^{\circ} \mathrm{C}\right)$ until reaching confluence after which the cells were divided or used for experiments.

For the primary neuronal cultures, hippocampi or cortex was dissected from E18 rat embryos or E16 TrkB ${ }^{\mathrm{F} 616 \mathrm{~A}}$ mouse embryos (kindly provided by Dr. David Ginty, Johns Hopkins University) and the tissue dissociated in papain solution (in mg: 10 DL-Cystein- $\mathrm{HCl}, 10 \mathrm{BSA}, 250$ glucose, ad $50 \mathrm{ml}$ PBS $\left(\mathrm{pH} \mathrm{7.4)} ; 10 \mathrm{~min}, 37^{\circ} \mathrm{C}\right)$. Next the cells were triturated and suspended in a medium containing $9.8 \mathrm{ml}$ of $\mathrm{Ca}^{2+} / \mathrm{Mg}^{2+}$ free $\mathrm{HBBS}, 1 \mathrm{mM}$ sodium pyruvate, $10 \mathrm{mM}$ HEPES (pH 7.2) and $10 \mu 1$ DNAse I. The cells were plated onto polyL-lysine (Sigma Aldrich) coated 12-48 well culture plates at a cell density of $130000 \mathrm{cells} / \mathrm{cm}^{2}$ (hippocampal) or $260000 \mathrm{cells} / \mathrm{cm}^{2}$ (cortical). Primary neurons were maintained in Neurobasal medium (supplemented with $2 \%$ B27, 1\% penicillin/streptomycin and 1\% L-glutamine) and supplemented with fresh medium every $3^{\text {rd }}$ day. TrkB ${ }^{\mathrm{F} 616 \mathrm{~A}}$ mice carry a mutation near the ATP binding of TrkB rendering the receptor susceptible for inhibition by the mutation-specific kinase inhibitor 1NMPP1 (Chen et al., 2005; Sallert et al., 2009).

2.3. ELISA

Conventional sandwich phospho-Trk ELISA was performed essentially as described earlier (Rantamäki et al., 2011). Specifically, cell homogenates (lysis volume $25-75 \mu \mathrm{l}$ ) were transferred directly from culture plates into pre-coated (sc-11-R, Santa Cruz Biotechnology, Santa Cruz, CA, USA; $1: 500-1000$ in Optacoat ${ }^{\mathrm{TM}}$; overnight at $\left.4^{\circ} \mathrm{C}\right)$ and pre-blocked $(2 \%$ BSA/PBS-T; $2 \mathrm{~h}$ at room temperature) white 96-well Optiplate ${ }^{\mathrm{TM}}$ (PerkinElmer Oy, Espoo, Finland) plates and 3\% BSA/PBS-T $(+2 \mathrm{mM}$ $\mathrm{Na}_{3} \mathrm{VO}_{4}$ to inhibit tyrosine phosphatases) added ad $200 \mu \mathrm{l}$. After overnight incubation at $4{ }^{\circ} \mathrm{C}$ the wells were washed with PBS-T $(4 \times 300 \mu \mathrm{l})$ and antiphosphotyrosine antibody added to the wells (in house biotinylated PY20; AbD Serotec, Kidlington, UK; $1: 1000$ in 2\% BSA/PBS-T; overnight at $4^{\circ} \mathrm{C}$ ). Following sequential washes and HRP-coupled streptavidin antibody incubation $\left(1: 10000\right.$ in $2 \% \mathrm{BSA} / \mathrm{PBS}-\mathrm{T} ; \mathrm{O} / \mathrm{N}$ at $\left.4^{\circ} \mathrm{C}\right) 100 \mu 1$ of ECL substrate mix was added to the wells and luminescence measured with Varioskan Flash plate reader (Thermo Fisher Scientific Oy).

For the in situ phospho-Trk ELISA, dissociated cells were directly plated onto UV-sterilized ELISA plates pre-coated and pre-blocked with sterilefiltered antibody and blocking solution, respectively. Following experimental treatment of cells, the plates were put immediately on ice, medium discarded and lysis buffer applied (10-25 $\mu 1)$. Next, the plates were rigorously shaken in a cold room for 30-60 min (800 rpm, Labsystems Wellmix, Thermo Fisher Scientific Oy) after which $3 \%$ BSA/PBS-T (+2 $\mathrm{mM} \mathrm{Na}_{3} \mathrm{VO}_{4}$ to inhibit tyrosine phosphatases) solution was applied ad $200 \mu 1$ (96-multiwell) or ad $50 \mu \mathrm{l}$ (384-multiwell). After overnight incubation at $4{ }^{\circ} \mathrm{C}$, the wells were washed and ELISA assay continued as described above. 

with vehicle or with Spectrum Collection compounds for 15 minutes $(5 \mu \mathrm{M}$ $\mathrm{n}=1 ;+37^{\circ} \mathrm{C}$ ) using Biomek FXp workstation (Beckman Coulter Finland Oy, Helsinki, Finland) and then post-stimulated with vehicle or with BDNF (5 $\mathrm{ng} / \mathrm{ml} ;+37^{\circ} \mathrm{C}$ ) for another 15 minutes using Multidrop Combi (Thermo Fisher Scientific Oy). After the stimulations, the medium was discarded, cells were lysed in ProteoJETTM membrane protein extraction buffer and ELISA analyses run as described. Compounds regarded as hits (response to BDNF \pm $3 \mathrm{x}$ standard deviation (STDEV)) were re-tested in triplicates and the compounds that still passed the hit criteria were analyzed in a dose-response assay $(0.25,1,5,25 \mu \mathrm{M} ; \mathrm{n}=3$ ) (inhibitors with and activators without BDNF post-treatment)

3.

We have previously developed a phospho-Trk sandwich ELISA based on commercial antibodies and reagents and used this assay to examine Trk phosphorylation in cell homogenates (Rantamäki et al., 2011). Briefly, lysed cell homogenates (reference lysis buffer: NP buffer) are transferred to and incubated on pre-blocked ELISA plates previously coated with an antibody directed against the intracellular domain of Trk receptors (reference antibody: sc-11-R, rabbit polyclonal; reference coating solution: phosphate buffered saline). Next, the wells are sequentially washed and incubated with biotinylated phospho-tyrosine antibody, streptavidin-HRP and chemiluminescence reagent, after which emitted light is quantified. Under these reference conditions, the assay readily detected BDNF-induced TrkB phosphorylation in MG87-trkB fibroblasts (Figure 1a), NGF-induced TrkA phosphorylation in PC12 cells (Figure 1b) and BDNF-induced Trk phosphorylation in primary mouse and rat neuronal cultures (Figure 1c-d) whereas no such neurotrophin-induction was seen in MG87 parental cells or in TrkB expressing cells pre-treated with Trk kinase inhibitors or if the capturing antibody was not present in the assay (Figure 1a, b-d). We furthe optimized the sampling and assay conditions by evaluating the influence of different lysis buffers, antibodies and coating buffers on signal-tobackground ratio (S/B) achieved with BDNF stimulation. The highest S/Bs were observed when the ProteoJET ${ }^{\mathrm{TM}}$ membrane protein extraction kit was used for the cell lysis (Figure 1e) and when the polyclonal rabbit pan-Trk antibody in Optacoat ${ }^{\mathrm{TM}}$ solution was used for Trk immunocapturing (Figure 1f-g). However, small lysate levels produced significantly lower S/B than higher lysate levels (S/B: $50 \mu \mathrm{g}<100 \mu \mathrm{g}=200 \mu \mathrm{g}$ ) (Figure 1h). Under optimized assay conditions, the $\mathrm{S} / \mathrm{B}$ remained unchanged for 7 minutes after application of chemiluminescence reagent (Figure 1i) and results obtained after 5 minutes were used for all described analyses.

\section{In situ phospho-Trk ELISA}

Next we sought to test whether the conventional sandwich phospho-Trk ELISA assay conditions can be transferred into an in situ set-up that would allow cell culturing, stimulation, lysis and phosphorylation analysis in the same plate (Figure 2a). Such in situ ELISA set-up has been previously utilized to examine the levels of secreted factors, including TrkB ligand BDNF (Balkowiec and Katz, 2000), but to the best of our knowledge not to examine intracellularly resident proteins such as transmembrane receptors. In our method, cells were directly cultured on pre-coated and pre-blocked ELISA plates. Following cell stimulations, the plates were immediately put on ice, medium discarded and cells lysed in situ by rigorous shaking in a

3.3. Proof-of-concept small molecule screening

We next performed a proof-of-concept small molecule screen to test the suitability of in situ phospho-Trk ELISA method for large-scale experimenta studies and for drug screenings. Biomek FXp automated workstation was used to pre-stimulate the MG87-trkB cells with vehicle or tested compounds prior to submaximal BDNF (5 $\mathrm{ng} / \mathrm{ml}, 15 \mathrm{~min}$ ) administration. Subsequent steps were performed manually. Actual screen consisted of primary (with BDNF) and secondary (repeat with and without BDNF) screens. With this approach, we were able to screen for compounds that would regulate TrkB signaling in BDNF dependent or independent manner. A compound was considered as a hit if it produced a signal differing from BDNF response for a minimum of $\pm 3 \times \mathrm{STDEV}$ ( of BDNF). The first set of compounds in the primary screen was evaluated in two independent but identical stimulation plates to assess the repeatability and quality of data (Figure 2d). Overall quality control values from the primary screen plates were as follows (value \pm STDEV): $Z^{\prime}$ factor $=0.25 \pm 0.19$, Coefficient of variation $(\mathrm{CV})=0.13 \pm 0.05$, $\mathrm{S} / \mathrm{B}=4.15 \pm 1.31$

Based on the primary and secondary screens, total of 26 compounds $(1.3 \%)$ were further evaluated in a dose-response setup. Compounds that positively modulate TrkB phosphorylation only in the presence of BDNF were not

small volume of lysis buffer (ProteoJET ${ }^{\mathrm{TM}}$ membrane protein extraction kit). Then $2 \%$ BSA/PBS-T (supplemented with tyrosine phosphatase inhibitor sodium vanadate) was added to the wells and immunocapturing of Trk receptors was achieved during overnight incubation; after this, the wells were washed and ELISA assay continued as described above.

In situ phospho-Trk ELISA readily detected BDNF-induced TrkB phosphorylation in MG87-trkB fibroblasts in both 96- and 384-multiwell formats; however, S/B was significantly higher in the former format (Figure 2b). The method also allowed detecting small but significant BDNF-induced ( $5 \mathrm{ng} / \mathrm{ml}, 15 \mathrm{~min}$ ) change in Trk phosphorylation in cultured E18 rat primary cortical cultures (6 days in vitro) (Vehicle: $100.00 \pm 4.70 \%$ vs. BDNF: $157.79 \pm 2.48 \% ; \mathrm{n}=8-16 ; \mathrm{P}<0.005$, two-tailed Student t-test).

Next we performed side-by-side analyses with conventional and in situ phospho-Trk ELISAs to directly compare the performances of these methods. Briefly, the MG87-trkB cells were grown and stimulated with BDNF in 96well cell-culture plates and transferred manually into 96-well ELISA plates or the cells were directly grown and stimulated in 96-well ELISA plates. Subsequent ELISA steps were performed identically thereafter. Although the in situ method is mechanistically more straightforward, the $\mathrm{S} / \mathrm{B}$ was significantly better with the conventional ELISA (Figure 2c).

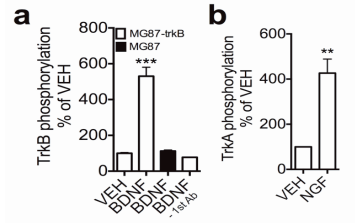

e

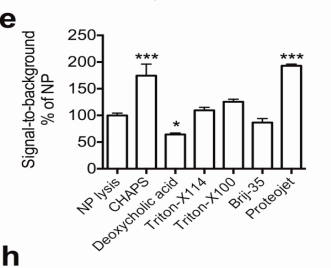

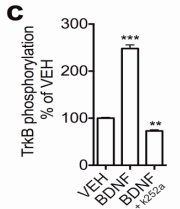

$\mathbf{f}$

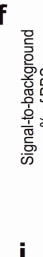

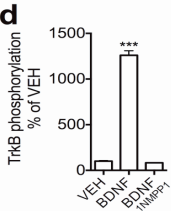

g

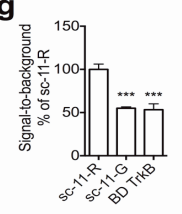

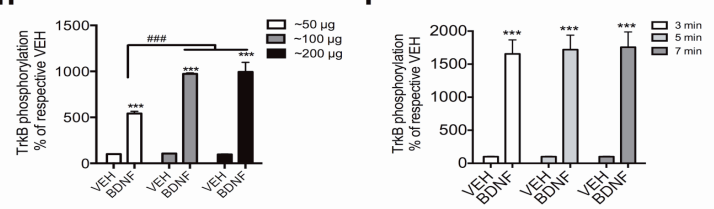

Figure 1. Characterization and optimization of sandwich phospho-Trk ELISA (a) The assay readily detects BDNF-induced $(5 \mathrm{ng} / \mathrm{ml}, 15 \mathrm{~min}$ ) TrkB phosphorylation in fibroblasts expressing TrkB (MG87trkB) but not in parental cells (MG87) or if the capturing antibody is not present in the assay ( $\mathrm{n}=3$ 4/group) (b) NGF-induced ( $5 \mathrm{ng} / \mathrm{ml}, 15 \mathrm{~min}$ ) TrkA phosphorylation in PC12 cells ( $\mathrm{n}=3 /$ group) (c) The assay readily detects BDNF-induced $(5 \mathrm{ng} / \mathrm{ml}, 2 \mathrm{~min})$ TrkB phosphorylation in E18 rat primary neuronal cultures whereas no signal is detected when the cultures are pretreated with kinase inhibito k252a (200 nM; $15 \mathrm{~min})$ (n=6/group) (d) The assay readily detects BDNF-induced ( $5 \mathrm{ng} / \mathrm{ml}, 15 \mathrm{~min})$ TrkB phosphorylation in E16 mouse primary neuronal cultures derived from TrkB ${ }^{\mathrm{F} 616 \mathrm{~A}}$ mutant mice whereas no signal is detected when the cultures are pretreated with mutation-specific kinase inhibitor 1NMPP1 (100 nM; 24 hours) (n=4/group) (e) The impact of tested cell lysis buffers on signal-tobackground ratio compared to reference buffer ( $\mathrm{n}=5$-6/group) (f) The impact of tested capture antibodies on signal-to-background ratio compared to reference antibody ( $\mathrm{n}=3$ /group) (g) The impact of tested coating solutions on signal-to-background ratio compared to reference solution ( $\mathrm{n}=3$-6/group) (h) The impact of lysate level (50-200 $\mu$ g) on signal-to-background ratio (n=3/group) (i) Signal-tobackground ratio ( $\mathrm{n}=3$ /group) at 3,5 and 7 minutes after addition of the chemiluminescence reagent. $* \mathrm{P}<0.05, * * \mathrm{P}<0.01, * * * \mathrm{P}<0.005$ of vehicle or reference condition, one-way ANOVA followed by Newman-Keuls post hoc (a, c-h) test or Student t-test (b, i). Abbreviations: Ab=antibody, $\mathrm{PBS}=$ phosphate buffered saline, $\mathrm{CB}=$ carbonate buffer.

found, and thus potential TrkB activators ( 8 compounds) were tested without BDNF. Since MG87-trkB cells show rather low basal phosphorylation status of TrkB (Rantamäki et al., 2011), potential TrkB inhibitors (18 compounds) were tested in the presence of BDNF. Of potential TrkB activators, only betamethasone valerate increased TrkB phosphorylation dose-dependently at doses 0.25-5 $\mu \mathrm{M}$ whereas most other compounds (amiloride, patulin, epoxygedunin, harmine, 7-deshydroxypyrogallin-4-carboxylic acid, sennoside A) regulated TrkB phosphorylation independently of concentration (Figure 2e and data not shown). If anything, camptothecin reduced TrkB phosphorylation (data not shown). Of potential inhibitors, 11 compounds (podofilox, tyrothricin, gramicidin, oxibendazole, podophyllin, laccaic acid A, picropodophyllin, tomatine, aurin tricarboxylic acid, 4 demethylepipodophyllotoxin, 4,4-diisothiocyanostilbene-2,2-sulfonic acid) dose-dependently reduced BDNF-induced TrkB phosphorylation (Figure 2f and data not shown). Interestingly, depending on dose, 5 compounds (tannic acid, fenbendazole, theaflavin, plumbagin, gossypetin) produced either inhibition or facilitation of BDNF-induced TrkB activation (Figure 2g). Two compounds produced only minor changes on BDNF-induced TrkB phosphorylation in the dose-response set-up (albendazole, deoxysappanone) (data not shown). 
In situ protocol

\begin{tabular}{|c|c|c|c|c|c|c|}
\hline \multicolumn{2}{|r|}{ Step } & Specification & $\begin{array}{c}\text { per/ } \\
96 \text { plate }\end{array}$ & $\begin{array}{l}\text { well } \\
384 \text { plate }\end{array}$ & ${ }^{\circ} \mathrm{C}$ & \multirow{2}{*}{$\begin{array}{c}\text { Time } \\
30 \mathrm{~min}\end{array}$} \\
\hline la & Plate sterilization & UV light & & & $+20^{\circ} \mathrm{C}$ & \\
\hline b & $1^{\text {st }}$ antibody & $\begin{array}{l}\text { sc-11-R in Optacoat } \\
(1: 500-1000)\end{array}$ & $200 \mu \mathrm{l}$ & $50 \mu \mathrm{l}$ & $+4^{\circ} \mathrm{C}$ & $24 \mathrm{~h}$ \\
\hline c & Blocking & $2 \%$ BSA in PBS-T $(0.01 \%)$ & $300 \mu \mathrm{ll}$ & $75 \mu \mathrm{l}$ & $+20^{\circ} \mathrm{C}$ & $2 \mathrm{~h}$ \\
\hline d & Wash & Medium & $200 \mu 1 \times 2$ & $50 \mu 1 \times 2$ & $+20^{\circ} \mathrm{C}$ & $5 \mathrm{~min}$ \\
\hline e & $\begin{array}{l}\text { Cell seeding + } \\
\text { cultivation }\end{array}$ & Medium & $140 \mathrm{\mu l}$ & $50 \mu \mathrm{l}$ & $\begin{array}{l}+37^{\circ} \mathrm{C} \\
\text { incubator }\end{array}$ & $24 \mathrm{~h}$ \\
\hline $2 a$ & Cell stimulations & \multicolumn{5}{|c|}{ (Optional) } \\
\hline b & $\begin{array}{l}\text { Media removal + } \\
\text { transfer on ice }\end{array}$ & Discard to sink & & & on ice & $1 \mathrm{~min}$ \\
\hline c & Cell lysis & $\begin{array}{l}\text { ProteoJET (shaking } \\
\text { 800rpm) }\end{array}$ & $25 \mu \mathrm{l}$ & $10 \mu \mathrm{l}$ & $+4^{\circ} \mathrm{C}$ & $60 \mathrm{~min}$ \\
\hline d & $\begin{array}{l}\text { Trk receptor } \\
\text { immunocapturing }\end{array}$ & $3 \%$ BSA in PBS-T (0.01\%) & ad $200 \mu \mathrm{l}$ & ad $50 \mu \mathrm{ll}$ & $+4^{\circ} \mathrm{C}$ & $24 \mathrm{~h}$ \\
\hline $3 a$ & Wash & PBS-T & $300 \mu \mathrm{x} \times 4$ & $75 \mu \mathrm{l} \times 4$ & $+20^{\circ} \mathrm{C}$ & $5 \mathrm{~min}$ \\
\hline b & $2^{\text {nd }}$ antibody & $\begin{array}{l}\text { PY20-biotin in blocking } \\
\text { buffer (1:1000) }\end{array}$ & $200 \mu \mathrm{l}$ & $50 \mu \mathrm{l}$ & $+4^{\circ} \mathrm{C}$ & $24 \mathrm{~h}$ \\
\hline $4 a$ & Wash & PBS-T & $300 \mu 1 \times 4$ & $75 \mu 1 \times 4$ & $+20^{\circ} \mathrm{C}$ & $5 \min$ \\
\hline b & $3^{\text {rd antibody }}$ & $\begin{array}{l}\text { Streptavidin-HRP in } \\
\text { blocking buffer (1:10000) }\end{array}$ & $200 \mu \mathrm{l}$ & $50 \mu \mathrm{l}$ & $\begin{array}{l}+4^{\circ} \mathrm{o}^{\circ} \\
+20^{\circ} \mathrm{C} \\
\end{array}$ & $24 \mathrm{~h} / 1 \mathrm{~h}$ \\
\hline $5 a$ & Wash & PBS-T & $300 \mu 1 \times 4$ & $75 \mu 1 \times 4$ & $+20^{\circ} \mathrm{C}$ & $5 \mathrm{~min}$ \\
\hline b & Reaction & ECL & $100 \mu \mathrm{l}$ & $25 \mu \mathrm{I}$ & $+20^{\circ} \mathrm{C}$ & $5 \mathrm{~min}$ \\
\hline c & Counting & & & & $+20^{\circ} \mathrm{C}$ & $0.1 \mathrm{~s} / \mathrm{well}$ \\
\hline
\end{tabular}

b

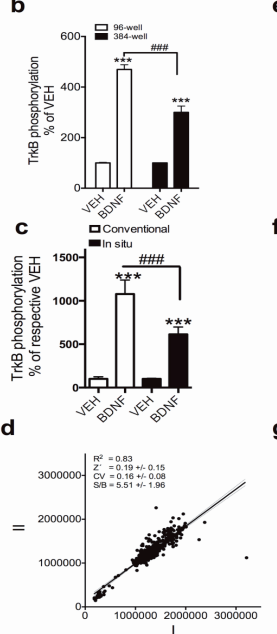

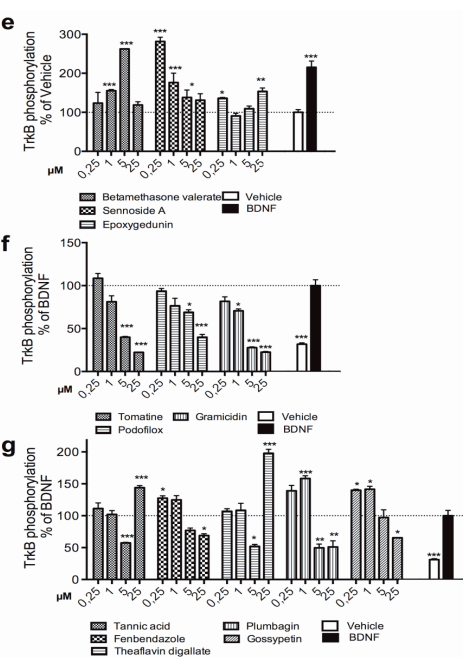

Figure 2. In situ phospho-Trk ELISA and its utilization for research and compound screening (a) In situ phospho-Trk ELISA protocol (b) In situ phospho-Trk ELISA readily detects BDNF-induced (5 ng/ml, 15 min) TrkB phosphorylation in MG87-trkB cells in 96- and 384-multiwell formats ( $\mathrm{n}=2-5 /$ group) (c) Comparison of conventional and in situ phospho-Trk ELISA methods (n=11-12/group) (d) X-Y plotted

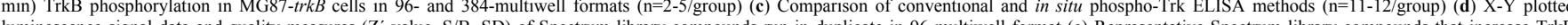
lute phosphos (compouts appled (f-g), Student t-test. \#\#\#<0.005, two-way ANOVA, followed by Newmann-Keuls post hoc test.

4.

\section{Discussion}

The main aim of this study was to test whether our previously developed (Rantamäki et al., 2011) and further optimized conventional sandwich phospho-Trk ELISA (Figure 1) can be developed into an in situ format, i.e. a method that would allow the cells to be directly cultured, receptors stimulated and Trk phosphorylation assayed on the same multiwell plate. As a single-plate assay this approach would encompass several advantages over conventional sandwich ELISA. Most importantly, it would make unnecessary to scrape and transfer cell homogenates from plate to plate and therefore would reduce the time, manpower and resources needed for performing the analysis. Moreover, Balkowiec and Katz $(2000,2002)$ have previously developed in situ ELISA that allowed detecting neuronally released BDNF with higher sensitivity than the conventional method. The in situ phospho-Trk ELISA readily detected BDNF-induced phosphorylation of TrkB receptors in fibroblasts expressing TrkB in 96- and 384-multiwell formats, albeit the $\mathrm{S} / \mathrm{B}$ ratio was lower in latter format, a finding that may be related to lower lysate amount (see Figure 1h) and thus absolute levels of TrkB protein in the 384-well format. BDNF-induced Trk phosphorylation was also detected in rat primary neuronal cultures, but the $\mathrm{S} / \mathrm{B}$ ratio was less than expected based on data obtained using conventional ELISA method and further optimization is needed for primary neuronal cultures employed for this approach. We also compared the $\mathrm{S} / \mathrm{B}$ achieved by submaximal BDNF stimulation in conventional and in situ Trk ELISA methods. Although the in situ method is mechanistically more straightforward and thus readily allows implementation to robotics, the S/B was significantly better with the conventional ELISA.

In order to further validate the developed in situ phospho-Trk method and investigate its suitability for large-scale analyses, including drug screening, we carried out semi-automated small-scale compound screening in 96-multiwell format. The method produced highly reproducible data in the screening setup.

Although we did not primarily aim at identifying novel compounds targeting TrkB signaling, we found several potential inhibitors and activators of TrkB from the Spectrum Collection compounds, a selected set of drug and drug-like chemicals, natural products and other bioactive compounds. Importantly, some of the compounds represent a chemical or pharmacological class that has been previously shown to increase TrkB signaling (e.g. synthetic glucocorticoid betamethasone valerate (Jeanneteau et al., 2008), gedunin derivative epoxygedunin (Jang et al., 2010)). Majority of potential TrkB inhibitors belong to anthelmintics (bendazole derivatives), antibiotics (e.g. gramicidin) or antiviral drugs (e.g. podophyllins). Interestingly, depending on dose, 5 compounds produced either inhibition or facilitation of BDNF-induced TrkB activation.

In conclusion, we describe a novel method that can be used to examine Trk receptor phosphorylation in cultured cells directly plated on antibody-coated multiwell plates. Principally similar methods can be developed to examine the levels and signaling of any cellular protein. Indeed, our preliminary studies indicate that the in situ ELISA approach can be utilized for the detection of phosphorylated Tau (data not shown), a microtubule assembly protein whose hyperphosphorylation has been implicated in the pathophysiology of neurodegenerative disorders.

\section{Competing interests}

H.H. is a co-founder and Chief Scientific Officer at Hermo Pharma Ltd. E.C. is a co-founder and shareholder of Hermo Pharma Ltd.

\section{Acknowledgments}

We would like to thank Outi Nikkilä and Anna Lehto for their excellent technical assistance.

\section{Financial disclosure}

This study was financially supported by the Finnish Funding Agency for Technology and Innovation (TEKES) (E.C.), Drug Discovery and Chemical Biology Network (Biocenter Finland) (L.T., P.T., K.W.), Doctoral Program Brain \& Mind (H.A.) and Hermo Pharma Ltd (E.C., T.R.).

\section{References}

Balkowiec A, Katz D. Activity-dependent release of endogenous brain-derived neurotrophic factor from primary sensory neurons detected by ELISA in situ. J Neurosci 2000;20:7417-7423

Balkowiec A, Katz DM. Cellular mechanisms regulating activity-dependent release of native brain-derived neurotrophic factor from hippocampal neurons. J Neurosci 2002;22:10399-10407

Chen X, Ye H, Kuruvilla R, Ramanan N, Scangos KW, Zhang C, Johnson NM, England PM, Shokat KM, Ginty DD. A chemical-genetic approach to studying neurotrophin signaling. Neuron 2005;46:13-21

Huang EJ, Reichardt LF. Neurotrophins: roles in neuronal development and function. Annu Rev Neurosci 2001;24:677-736

Jang SW, Liu X, Chan CB, France SA, Sayeed I, Tang W, Lin X, Xiao G, Andero R, Chang Q, Ressler KJ, Ye K. Deoxygedunin, a natural product with potent neurotrophic activity in mice. PLoS One 2010;5:e11528

Jeanneteau F, Garabedian MJ, Chao MV. Activation of Trk neurotrophin receptors by glucocorticoids provides a neuroprotective effect. PNAS 2008;105:4862-4867 Longo FM, Massa SM. Small-molecule modulation of neurotrophin receptors: a strategy for the treatment of neurological disease. Nature Rev Drug Discovery 2013;12:507-525

Rantamäki T, Castrén E. Targeting TrkB neurotrophin receptor to treat depression. Expert Opin Ther Targets 2008;12:705-715

Rantamäki T, Hendolin P, Kankaanpää A, Mijatovic J, Piepponen P, Domenici E, Chao MV, Mannistö PT, Castrén E. Pharmacologically diverse antidepressants rapidly activate brain-derived neurotrophic factor receptor TrkB and induce phospholipase-Cgamma signaling pathways in mouse brain. Neuropsychopharmacology 2007;32:2152-2162

Rantamäki T, Vesa L, Antila H, Di Lieto A, Tammela P, Schmitt A, Lesch KP, Rios M, Castrén E. Antidepressant drugs transactivate TrkB neurotrophin receptors in the adult rodent brain independently of BDNF and monoamine transporter blockade. PLoS One 2011;6:e20567

Saarelainen T, Hendolin P, Lucas G, Koponen E, Sairanen M, MacDonald E, Agerman K, Haapasalo A, Nawa H, Aloyz R, Ernfors P, Castrén E. Activation of the TrkB neurotrophin receptor is induced by antidepressant drugs and is required for antidepressant-induced behavioral effects. J Neurosci 2003;23:349-357

Sallert M, Rantamäki T, Vesikansa A, Anthoni H, Harju K, Yli-Kauhaluoma J, Taira T, Castrén E, Lauri SE. Brain-derived neurotrophic factor controls activitydependent maturation of CA1 synapses by downregulating tonic activation of presynaptic kainate receptors. J Neurosci 2009;29:11294-11303

Segal RA, Bhattacharyya A, Rua LA, Alberta JA, Stephens RM, Kaplan DR, Stiles CD. Differential utilization of Trk autophosphorylation sites. J Biol Chem 1996;271:20175-20181

Thiele CJ, Li Z, McKee AE. On Trk--the TrkB signal transduction pathway is an increasingly important target in cancer biology. Clin Cancer Res 2009;15:59625967

Vesa J, Kruttgen A, Shooter EM. p75 reduces TrkB tyrosine autophosphorylation in response to brain-derived neurotrophic factor and neurotrophin 4/5. J Biol Chem 2000;275:24414-24420 